\title{
Limberg Flap is a Safe and Effective Procedure for the Surgical Treatment of Pilonidal Sinus in Sacrococcygeal Region
}

\author{
Islam MR', Matin ABMA², Ahmad S ${ }^{3}$, Islam MA', Alam SI ${ }^{5}$
}

Conflict of Interest: None

Received: 31.03 .2020

Accepted: 04.04 .2020

www.banglajol.info/index.php/JSSMC

\section{Key Words:}

Limberg flap, pilonidal sinus, sacrococcygeal region, recurrence and complications.

\begin{abstract}
:
Pilonidal sinus in the sacrococcygeal region is an acquired condition and usually seen in young male adults. Diagnosis is indicated by to see the site and appearance of chronic discharging opening, and identification of midline pit in the natal cleft. The management of the sacrococcygeal pilonidal sinus varies from clipping of hairs with good hygiene of the area, wide excision of the area with primary or secondary closure and newer flap procedures, but none is widely accepted. The main concern for the treatment to the patient is the recurrence. This prospective study has been performed to determine the effectiveness and safety of the Limberg flap procedure for sacrococcygeal pilonidal sinus for new and recurrent cases. Primary end point was rate of recurrence and secondary end points were its complianceand complications such as wound infection, postoperative pain and return to work. A total of 17 patients were operated from March 2012 to June 2016.Both primary and recurrent diseases were included. All patients successfully underwent surgery. Patients complained very minimal postoperative pain. LO were average 2 days. All patients were discharged with negative suction drain in situ. Drains were removed on $7^{\text {th }} P O D$ and stitches were removed on 9 th to 12 th postoperative day. All patients returned to work after 2 nd weeks. In our study no recurrence or major complications were found. Limberg flap for sacrococcygeal pilonidal sinus was found very useful and effective in terms of recurrence rate and patients morbidity.
\end{abstract}

[J Shaheed Suhrawardy Med Coll 2020; 12(1): 6-8] DOI: https://doi.org/10.3329/jssmc.v12i1.51611

\section{Introduction:}

The name pilonidal is derived from Latin meaning "nest of hairs". Pilonidal sinus is a chronic discharging sinus which contains tuft of hairs within it. The condition may occur in different parts of body but most commonly seen in the upper half of the gluteal cleft, that is, in the sacrococcygeal region. ${ }^{1,2}$ Sacrococcygeal pilonidal sinus is a common disease of the adult age group, especially male population. The condition causes significant morbidity from both disease itself and from the surgery done for it two. It is an acquired condition. Excessive hairiness and presence of deep natal cleft are predisposing factors for the disease. ${ }^{2,3}$ Karydakis proposed that hair

1. Dr. Md. Rashidul Islam, Associate Professor, Colorectal surgery, Shaheed Suhrawardy Medical College, Dhaka.

2. Dr. Abul Bashar Md. Abdul Matin, Associate Professor, Department of Surgery, Sheikh Sayera Khatun Medical College, Gopalganj.

3. Dr. Sami Ahmad, Associate Professor of Surgery, Shaheed Suhrawardy Medical College, Dhaka.

4. Dr. Md. Armanul Islam, Resident Surgeon (General), Shaheed Suhrawardy Medical College and Hospital, Dhaka.

5. Dr. Shoaeb Imtiaz Alam, FCPS Part- II Course Student, Dhaka Medical College and Hospital.

Correspondence: Dr. Md. Rashidul Islam, Associate professor, Colorectal surgery, Shaheed Suhrawardy Medical College, Dhaka. Mobile: +88017111279298, E-mail: rashidulbsmmu@gmail.com with chisel like roots insert itself into the natal cleft leading to foreign body tissue reaction and infection. ${ }^{4}$ Diagnosis is indicated by the site and appearance of chronic discharging opening, and identification of midline pit in the natal cleft. The management of the sacrococcygeal pilonidal sinus varies from clipping of hairs with good hygiene of the area, wide excision of the area, and newer flap procedures, but none is widely accepted.$^{5}$ The main concern for the treatment to the patient is the recurrence. Many reasons were attributed to recurrence, such as leaving behind some tracts, sutures in midline causing more trauma with repeated infection, accumulation of perspiration, and friction with tendency of the hair getting incorporated into the wound. Limberg rhomboid flap for sacrococcygeal pilonidal sinus was designed by Limberg in $1946 .{ }^{6} \mathrm{He}$ described a technique for closing a $60^{\circ}$ rhombus-shaped defect with a transposition flap. The advantages of this flap were multifactorial. It was easy to perform, with sutures away from the midline giving rise to a tensionless flap of unscarred skin in the midline, which helps in good hygiene maintenance, reducing sweating maceration, erosions, and scar formation. It has been shown from different studies that Limberg flap reconstruction following excision of the sinus area is 
superior to primary closure and other flap procedures. The procedure is also a safe and reliable method in surgical treatment of sacrococcygeal pilonidal sinus disease. The studies also show that it has low complication and recurrence rates. ${ }^{2,3,4}$ This prospective study has been performed to determine the effectiveness and safety of the Limberg flap procedure for sacrococcygeal pilonidal sinus. Primary end point was to determine the rate of recurrence and secondary end points were to evaluate patient compliance and complications such as wound infection, postoperative pain and return to work.

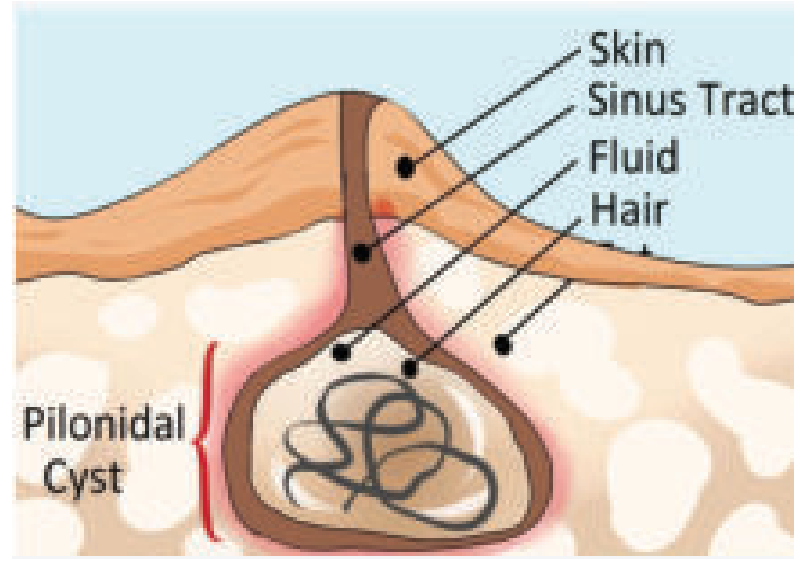

Fig.-1: Pilonidal Disease.

\section{Materials and Methods:}

A total of 17 patients were operated from March 2012 to June 2016. All patients were male and their age range between 15 to 33 years.(Fig-1) Both primary and recurrent diseases were included. Operations were performed in prone position. Spinal anesthesia was given to all patients. Methylene blue dye was introduced through the secondary opening to include all pathological tissues to be excised. Standard length and breadth ratio of 10:6 was applied. (Fig-2)

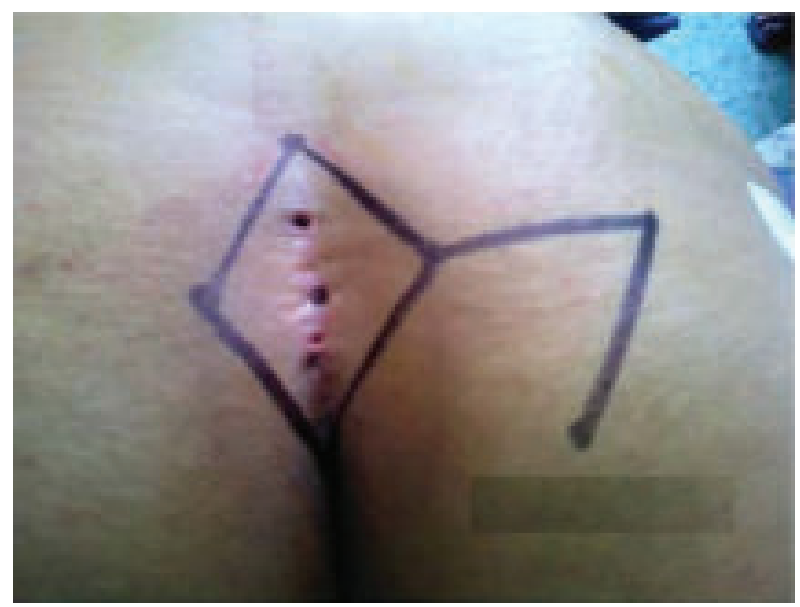

Fig 2 Showing initial markings ofLimberg flap
Tissues excised up to sacral fascia. Hemostasis were secured. Limberg flaps were created with intact blood supply and without any tension. (Fig-3)

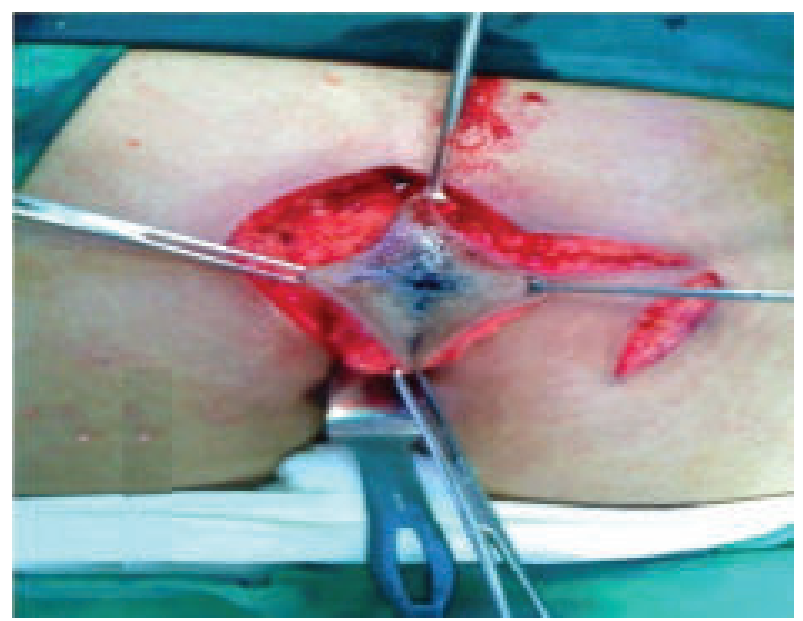

Fig 3 showing construction of Limberg Flap

Negative suction drain was kept in all cases. Skin was closed by $3 / 0$ prolene(Fig-4)

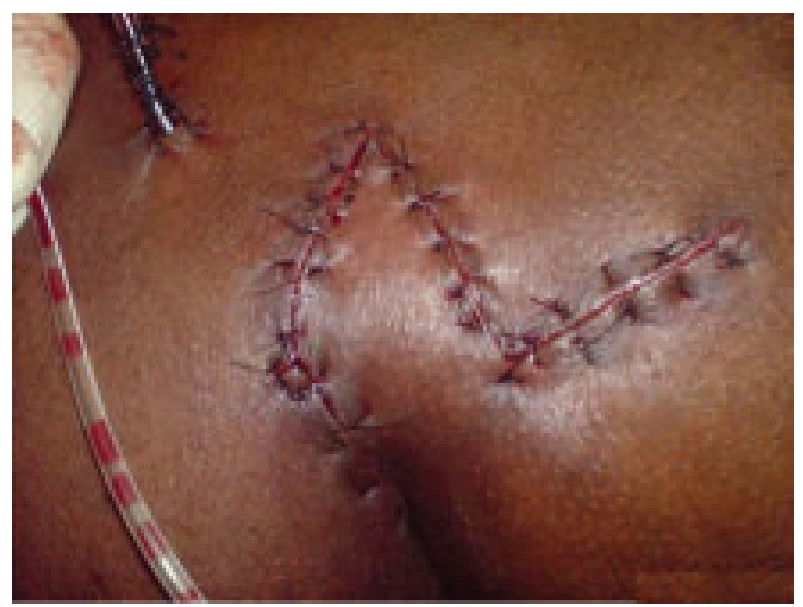

Fig.-4: Showing final picture after closure of wound

Drains were removed on 5 th to 7 th POD and stitches were removed on 9th to 12 th POD. All patients successfully underwent surgery. Cefuroxime and clavulonic acid combination antibiotic was used. Ketorolac was used as analgesics. Patients were discharged on 2nd to 3rd POD with drain in situ. Patients were followed up for at least two years.

\section{Results:}

In our study most of the patients are in the age group in 16- 20 and 21-25. 


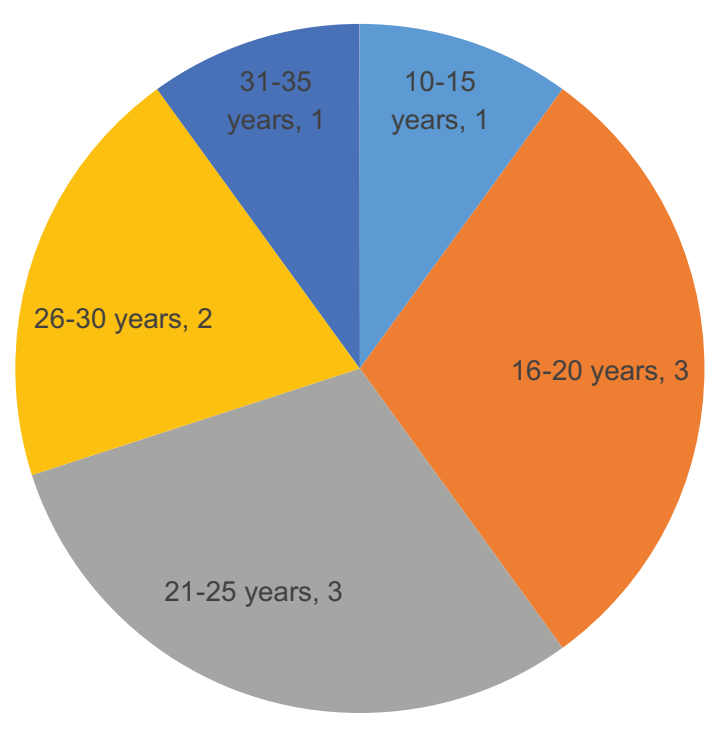

Fig.-5: Showing age distribution of the patients $(n=10)$

Most of the patients complained very minimal postoperative pain. Length of hospital stay were average 2-3 days. All patients returned to work after 2nd weeks. In our study no recurrence were found. 3 patients developed complications like wound infections, partial thickness marginal flap necrosis or seroma formation. Patient compliance was good.

\section{Discussion:}

Curative surgical treatment for sacrococcygeal pilonidal sinus is always a great challenge for the surgeons because the disease is notoriously recurring. Principle of surgical treatment for this sinus is by the way of excision of the diseased tissue down to the sacrococcygeal fascia. But the next step of closure of the defect is a matter of concern. In this circumstances surgeon has to take into account of patient compliance, postoperative pain, infection and recurrence rates, hospital stay, frequent wound dressings, and cosmetic outlook. Closure of the defect with Limberg flap has many advantages. It is easy to perform and design. The flap flattens the natal cleft. It contains large vascularized pedicle and it can be sutured without tension. This in turn maintains good hygiene, reducing the friction, preventing maceration, and avoiding scar in the midline. This flap procedure has been found to be better than simple excision and closure, marsupialization, other flap procedures such as Bescom and Karydakis. ${ }^{7,8}$ Several series reported recently about the usefulness of this flap in treatment for sacrococcygeal pilonidal sinus. The outcomes of these studies have been comparable with our series in terms of complications and recurrences. Katsoulis had 25 patients, with 16 of them having complications with no recurrences. ${ }^{9}$ Aslam had 110 patients, with 5 of them having complications and 1 recurrence.$^{10}$ Urhan and Mentes also mentioned about a few complications in their studies. ${ }^{11,12}$ In our series there were three complications. No recurrence was reported till the time of study.

\section{Conclusion:}

Limberg rhomboid flap for surgical management of sacrococcygeal pilonidal sinus was found very useful and effective in terms of recurrence rate, wound and flap complications and patient compliance. In addition we have to advise the patient to reduce weight, avoid prolong sitting, maintain hygiene with regular shaving of the area and mid portion of back. Still we have to do large scale study to find the best way to treat pilonidal disease.

\section{References:}

1. Akca T, Colak T. Primary closure with Limberg flap in treatment of pilonidal sinus-randomized clinical trial. BJS. 2005;5074:1081-1084.

2. Srikanth K. Aithal, C. S. Rajan, Narender Reddy. Limberg Flap for Sacrococcygeal Pilonidal Sinus a Safe and Sound Procedure. Indian J Surg. 2013 Aug; 75(4): 298-301.

3. Mulla SA et al. Int Surg J. 2017 Feb;4(2):496-499 4. Akca T, Colak T. Primary closure with Limberg flap in treatment of pilonidal sinus-randomized clinical trial. BJS. 2005;5074:1081-1084.

4. Clothier PR, Haywood IR. The natural history of the post anal pilonidal sinus. Ann R College Surg England. 1984;66(3):201203.

5. Brearley R. Pilonidal sinus: a new theory of origin. Br J Surg. 1955;43:62-68.

6. Azab AS, Kamal MS, Saad RA, Abount AL, Atta KA, Ali NA. Radical cure of pilonidal sinus by a transposition rhomboid flap. BJS. 1984;71(2):154-155.

7. Bascom J. Pilonidal disease: origin from follicles of hairs and results of follicle removal as treatment. Surgery. 1980;87:567572 .

8. Karydakis GE. Easy and successful treatment of pilonidal sinus after explanation of its causative process. Aust NZJ Surg. 1992;62:385-389.

9. Katsoulis IE, Hibberts F, Carapeti EA Outcome of treatment of primary and recurrent pilonidal sinus with Limberg flap. Surgeon 2006;4(1):7-10, 62

10. Aslam M, Choudhry A.Use of Limberg flap for pilonidal sinusa viable option. J Ayub Med Coll Abbottabad.2009; 21(4):223225

11. Urhan MK, Kuckel F, Topgul K, Ozer I, Sari S. Rhomboid excision and Limber flap for managing pilonidal sinus: results of 102 cases. Dis Colon Rectum. 2002;45:656-659.

12. Mentes BB, Leventoglu S, Cihan A, Tatlicioglu E, Akin M, Oguz M. Modified Limberg transposition flap for sacrococcygeal pilonidal sinus. Surg Today. 2004;34(5):419-423. 